zu haben, dem erschöpften Körper neue Kraft, dem Geiste neuen Muth einflüsste. Diese Erfahrung machte auch ich, als ich nach nicht geringer Anstrengung den Gipfel erreichte.

(Schluss folgt.)

\title{
Die Wirkung des Mondes auf die Gewächse.
}

Ehe Ebbe und Fluth, als Product der Anziehungskraft des Mondes erkannt und wissenschaftlich nachgewiesen wurde, konnte man jegliche Wirkung des Mondes auf die Yflanzenwelt als Aberglauben verschreien, und im guten Glauben dahin arbeiten: sie als Vorurtheile und thörichte Annahme ausrotten zu müssen. So mag schon manche vorzügliche Kenntniss, gestützt auf die Erfahrung eines langen prüfenden und beobachtenden Lebens, verloren gegangen sein; weil man nicht dem Aberglauben dienen wollte. - Und Kenntnisse und Erfahrungen dieser Art, Wirkung des Mondes auf die Pflanzenwelt, möchten wir vergeblich von der Retorte des Chemikers und allen seinen physikalischen Apparaten erwarten. Denn wir haben hier einen mitwirkenden Factor, uns unwägbar und unmessbar, wechselnd, wie der Mond selbst in seinen Phasen. Oder sollte der Mond nicht auf die Pflanzen wirken, der doch auf die ganze irdische Natur, selbst den Menschen wirkt, der doch der Pflanzenwelt am fernsten steht? Wenn uns grosse Physiologen den aufsteigenden und absteigenden Saft der Bäume nachweisen, haben wir hier nicht eine geheime Wirkung des Mondes? - Wird also Keiner an der Einwirkung des Mondes hier aus Eigensinn zweifeln, bloss aus dem Grunde nicht zu glauben, als was man sieht. --. Indem ich hier nur einige dieser Probleme anführe, welche man früher dem Monde auf Saat und Ernte zuschrieb, so wenige es übrigens sind, welche zu meiner Kennıniss gekommen; so möchte ich Forscher und Freunde der Natur dadurch gewinnen, auch ihre Erfahrungen mitzutheilen; dass die helle und prüfende Gegenwart erforsche, was Wahrheit ist, und was Täuschung; wo eine Wirkung erzielt wird, und welche, oder was als Wahn und Aberglauben verbannt bleiben muss. - Und ergäbe sich gar kein Resultat, das Gewinn für Gärtner oder Landwirth ist; so möchte schon die Beobachtung und Erforschung Gewinn genug sein; denn die Wahrheit suchen, ist ja der Endzweck aller Philosophie.

Kartoffeln soll man setzen, wenn der Mond im Zeichen des Krebses steht, dann werden sie fruchtbar. Wie die Kartoffeln, so muss man auch Alles, was rankt, Bohnen, Erbsen, Wicken, Gurken, Kürbis, Hopfen, im Zeichen des Krebses setzen, so wachsen sie schön, und die Hülsenfrüchte kochen weich und schmackhaft. Setzt man Erbsen, Bohnen und Wicken in Vollmonde, so tragen sie recht voll, verlieren aber die Eigenschaft weich zu kochen. - Doppelte Blumen müssen im Vollmond gesät, oder nach Beschaffenheit des Stammes gelegt werden, das befördert ihre Vollheit. - Bäume und Gesträuch müssen im abnehmenden Monde beschnitten werden, es darf keine Gegenwirkung stautinden; der Mond zunehmen, und die Bäume abnehmen. Fruchtbäume soll man in der Neujahrsnacht grüssen, so werden sie sich 
dankbar beweisen und sehr fruchtbar sein. Oder man gibt ihnen etwas zu tragen, einen Strohbund in den Asten, oder einen eingeklemmten Stein ; so tragen sie auch reichlich Früchte (?) Diese beiden letzten Anführungen stehen aber nicht in Beziehung auf den Mond, und gebören nach der Ueberschrift nicht hierher.
Alí-Reetz im Juli 1855.
J. S chäde.

\section{Uebersicht}

der in der rheinischen Flora vorkommenden Species, Varietäten, Formenund Hybridender Gattung Mentha L.

Von Dr. Ph. Wirtgen.

(Fortselzung.)

B. Trichomentha: Blumenkronenröhre inwendig zottig.

a.M. aquaticae (W a s s e $\mathrm{m}$ ü $\mathrm{nz} \mathrm{n}$ ): Nüsschen warzig, selten an der Spitze auch bärlig.

8. Mentha aquatica L. Blüthenquirle an der Spitze des Stengels in einen Kopf zusammengedrängt; Blätter eiförmig, gesägt, geslielt, mehr oder weniger behaart, selten etwas filzig; Kelchzipfel langgespitzt; Kelchmündung behaart. Varietäten: $\alpha$. M. aquatica L. Blätter behaart, mit abgerundeter oder etwas vorgezogener Basis, gestielt, scharf-gesägt. Häufig an Gräben und Bächen bei Coblenz. Nro. 28. (Ed. I, 22.) Forma pedunculata: untere Halbquirle langgestielt. An der Nette und Lahn. Nro. 29.

B. M. hirsuta L. Blätter grauhaarig mit schwach-herzförmiger Basis, kurz-gestielt, seicht-gesägt. An Bächen und Gräben, jedoch nicht unmittelbar am Wasser. Nro. 30. (Ed. I, 40.)

Forma umbrosa $\mathrm{W} \mathrm{tg}$. Mit kleinerer Blumenkrone, eingeschlossenen Staubfäden und weit hervorstehendem Griffel. An beschatteten Stellen an der Nette und Lahn. Nro. 31.

Var. $\gamma$. verticillata (subspicata). Bläthenquirle zahlreich und alle durch hervortretende Deckblätter gestützt. An der Ues bei Bertrich. Nro. 32. (Ed. I, 41.)

\section{Bastarde.}

$5 \alpha .+8 \alpha$. M. sylvestre $=$ hirsuta Wtg. M. nepetoides Lej. Blüthenstand dickährig bis kopfig; Blälter gestielt, eiförmig mit vorgezogener Basis; ganze Pflanze zottig. Nro. 33. (Ed. I, 21.)

5 \% +8 .. M. incano $=$ hirsuta? W t g. M. hirta W ill d.en. Nüsschen warzig und bärtig; Blüthenähre dick-cylindrisch; Blätter gestielt, eiförmig, behaart. Die Hybridität und die Herkunft dieser Pflanze sind mir noch nicht klar; für die Hybridität sprechen die abortirenden Früchte und das auf einzelne Puncte beschränkte Vorkommen, dagegen - dass sie auch an Stellen vorkömmt, wo eine der beiden fraglichen 